\title{
Waiting for the Next Part: \\ How the Temporal Dimensions of Digital Serialisation Have Changed Author-Reader Dynamics
}

\author{
GABRIEL E. ROMAGUERA, University of Rhode Island, Kingston Campus
}

\begin{abstract}
A work of serial fiction is defined as 'a continuing story over an extended period of time with enforced interruptions' (Hughes \& Lund 1991, 1). It is that "enforced interruption" which makes for a temporal and spatial pause between the author, the reader, and the text. The distribution and publication of instalments for traditional print publishing and print comics works on strict schedules but this is not necessarily the case for digital comics. This paper explores how the serialization of webcomics functions with both defined and indeterminate publication schedules and how this affects the author-reader relationship. It uses textual criticism to better explain the publication aspects of narrative production and adapts these concepts to digital comics and their serialization. The analysis focuses on Rich Burlew and Tarol Hunt, two professional webcomic cartoonists who continue to search for the best publication schedule for their authorial processes.
\end{abstract}

\section{KEYWORDS}

Serialisation, author-reader relationship, webcomics. 
The process of reading requires patience. Engaging with a work of literature takes time as one goes from cover to cover of the text, though one has the power to skip to the end at any moment. In plays, films, television, and other forms of performances, the reader now becomes a viewer, who must wait patiently until the showing has run its time. Only when viewing these texts on a DVD or similar digital document can one exert control over the pace of the storytelling. But when the narrative is published over time, the readers' patience is tested even more so as the process of serialization ensures that only a fraction of the narrative is available. This paper analyses this additional temporal dimension in the author's narrative production, the readers' reception, and the relationship between the two within a digital context.

A work of serial fiction is defined as 'a continuing story over an extended period of time with enforced interruptions' (Hughes \& Lund 1991, 1). It is that "enforced interruption" which makes for a temporal pause in which the reader waits for the next part of the story to become available once it is published. The narrative respite in serialisation is also spatial, as the text continues in a different document. Each instalment is just one part of the overall text wherein every piece should have enough narrative material to stand on its own. However there are no objective forms of judgment to determine what "enough" is. The physical amount of content can be part of an industry standard, as is the case of television programs or comic books where a strict minimum must be adhered to. Or it can be the left up to the author or editor to decide the amount, as is the case with self-published books and graphic novels. In the case of digital content, authors follow a self-publication model that has no guidelines when it comes to content per instalment or the amount of time between each one. In a webcomics.com article titled ...But What about LongForm Comics?, Brad Guigar (the site's main editor) posits that each instalment should have enough content for current readers to feel that they have not wasted their time, while giving enough content for even new readers to understand what is going on within that moment in the text. He instructs would-be webcomic cartoonists to:

Make every comic as significant as possible: Translated for a long-form dramatic comic, this should read as such: Make sure every update is a satisfying experience for all of your readers. For a humor comic, it's a well-crafted punchline. For a dramatic comic, it might be a strong plot hook or a significant cliffhanger. But here's the rub, that update has to be satisfying to both your regular readers as well as the ones who are arriving at your site for the first time that day. In other words, it has to be significant without the aid of your archives. If you can achieve that, you can hold the new readers your site attracts (2009).

For those that are following the webcomic serially, the newest instalment has to be at least perceived as worth the time of the "enforced interruption". The availability of an online archive of any and all previous instalments provides a level of narrative accessibility that few other forms of serial fiction have and this will be discussed later in the paper. Still, for all the unwritten rules, suggestions and expectations, authors of webcomics still have the liberty to self-publish as they see fit, sometimes to the readers' dismay.

The freedom of content provides authors with a degree of leeway in what their webcomic can actually be, to the point that the demarcation of the medium becomes blurred. Guigar et al. in How to Make Webcomics provide the following definition to just what webcomics are and can be: 
To put it in the simplest equation: webcomics are comics + Web. They are everything you loved about long-form comics, short-form comics, sequential strips and single panels - transposed to a new means of distribution $(2008,13)$.

While webcomics can also apply to any kind of comics published online, this paper focuses on material specifically designed by authors with online publishing in mind. Comics of all forms and genres can be found within webcomics and authors are free to change between styles with each instalment. This freedom of narrative production and publication allows authors a certain independence that is not available in other media. Still, that liberty also extends to the readers of webcomics who have a high level of accessibility to the author thanks in part to the digital document in which the text is published. Tools like email, social media, and forums within the website publishing the comic can put a direct line of communication between reader and author. While these forms of interaction, especially social media, are readily available for communication between authors and readers of all media, the downtime to make each instalment of a webcomic is so minimal that readers can have a direct impact on the narrative's development. I specify this type of serialization as "microserialization" wherein each instalment makes up less than one percent of the overall narrative originally intended. ${ }^{1}$ Microserials can be found in other media but are particularly common to webcomics because instalments are potentially published very quickly and often.

To better understand the nuances of narrative production I have adapted aspects of textual criticism. This is a critical theory based on the process of publishing manuscripts and different editions, which I have used to analyse webcomic authorship. One of the main theorists of this field is George Thomas Tanselle, whose seminal book A Brief Rationale of Textual Criticism (1992) contains many ideas that have guided my study of contemporary serials within various media. Tanselle makes a distinction between the terms "work", "text", and "document" which are particularly instrumental to this paper. These terms (especially the first two) are often interchangeable when referring to the literary creation of an author, but I will be using them according to Tanselle's definition. Tanselle defines the 'work' as the 'ineluctable entity, which one can admire or deplore but cannot alter without becoming a collaborator with its creator (or creators)' $(1992,14)$. The 'text' is the 'tangible records of creativity' $(1992,20)$, and the 'document' is 'the received texts of the work' $(1992,28)$. In other words, the work exists as a concept within the author's mind that must be brought to fruition. Before a single word is written and even after its publication, the work is ephemeral and malleable but only by the author. The text is the physical embodiment of the work as the author gives shape to his/her thoughts through language. While the common perception of the text is the manuscript, it can be an amalgam of multiple notes in various sources with annotations and changes done by the author and editors. The document is how the reader can perceive the text, usually after the publication process. Alterations to individual documents (e.g. highlighting, annotating, or other marks to pages) are quite common, but in order to change the text itself the author (or someone with the authorial authority to do so) must publish an amended version of the text via a new publication of the document. Simply put, imagine the three stages of water. The work is like vapour, barely perceivable and shapeless. The text is fluid, visible but still without set boundaries. The

\footnotetext{
${ }^{1}$ The term was originally defined by webcomic cartoonist Robert $\mathrm{T}$. Balder in a personal interview I conducted via e-mail (2009).
} 
document is frozen with its form clearly defined by the medium of publication. The author condenses and eventually encapsulates the story so that readers can have it.

In the context of serialization, the stages of work, text, and document become problematized even more so than with traditional print publishing. The work continues to be overarching but can be limited to a certain number of years when a particular title has been serialized for so long that multiple authors have worked on it. For example, Grant Morrison's time writing Batman spanning from issue \#655 'Batman and Son' (2006) and ending with issue \#683 'Last Rites' (2008) is officially "his" work within the series. However, his stories on other DC titles affect the overall continuity and narrative surrounding the character's mythos. Since digital comics rarely change writers this is very rare, but there are a few cases of the artist changing, as was the case with the webcomic Erfworld (2006) which has always been written by Rob Balder but has been drawn and coloured by Jaime Noguchi, Xin Ye, and now by David Hanh. The text encompasses all instalments in all versions by all authors, even the ones that have not been written yet. The text changes with each additional part added to it during serialization, while existing parts of the story can be altered through newer instalments. The document is each individual instalment but also the trade paperbacks, the reprints, the compilations, and the omnibus editions. Digital documents encompass each subsection a website (like the blog and forums) within the structure of the site as a whole, where the author also works as the webmaster (or instils that authorial performance onto someone else). Alterations to the text can be done almost instantaneously through this format and affect all readers from that point on. New editions of the text through the updated document of the website automatically replace the previous version. There are no "early editions" of the webcomic available to readers unless they use digital archival services like the Wayback Machine (1996), which take and store snapshots of websites over time.

The shifting nature of the digital text and the document is reminiscent of John Bryant's concept of textual fluidity. In his book The Fluid Text, Bryant explains that, 'fluid texts, insofar as their material versions register these breakdown revisionary acts, are, from the moment of genesis and on into print, a constant 'deferral' of the literary work itself' $(2002,10)$. This "literary deferral" is variable between the time a change is needed and the time a change is implemented on the text. Once the process is undertaken, it is much faster in the digital format than compared to revisions and retractions in print. Since the webcomic cartoonist is often the solitary author of the work (and since there is no need for editors to serve as gatekeepers to digital publishing), any such changes are often indicated by the readers themselves. The author can choose to implement the fix, as is the case with typographical mistakes, often within minutes of initial publication of an instalment. It is important to note that many (if not all) aspects of narrative production, publication, and other aspects of running a webcomic are also done by this singular author. In his book Resisting Texts (1997), textual critic Peter Shillingsburg distinguishes these facets of authorship as 'textual performances'. These textual performances include the 'creative performance' where the literary work is first invented, the 'production performance' where it is ready to be transmitted or published, and the 'reception performance' where the reader interprets the text (76-78). I encompass all of Shillingsburg's types of performances into the umbrella term of "authorial performances" which better incorporates the explanations of the toils that go into all aspects of being an author, especially within microserialized digital fiction. 
For the purposes of this paper, I have focused on two similar ongoing webcomics whose authors have been publishing their works for years and have altered their publication schedule various times to different responses. Rich Burlew of Order of the Stick (OOTS) (2003) and Tarol Hunt of Goblins: Life through Their Eyes (2005) are each in charge of both the writing and art for their respective webcomics. Both webcomics fall under the fantasy gaming genre, as the main characters of each text are a group of heroes undertaking epic adventures. Their characters are also very much aware that they live within a world that follows the rules of the Dungeons \& Dragons (D\&D) game, specifically the 3.5 edition of the ruleset (Tweet et al 2003). This metaawareness is often the source for much of the humour in the comics. Comedy was once the central focus of both webcomics but they both underwent 'Cerebus Syndrome' in which the humour takes a backseat to more serious events within the overarching narrative. Cerebus Syndrome was first defined by Erik Burns-White (2006) and later updated by webcomic historian T. Campbell, who subdivided it into three phases: Pure humour, dramatic turn, and tonal juggling (2006). The transformation of these works changes not only the type of narrative but also the kind of reader that is expected to be part of the continued serialization. Jokes about $D \& D$ and epic fantasy dramas draw similar crowds but a more serious turn in the narrative affects the intended readership and the story's transformation can attract or alienate the potential audience. While the changes in style can be considered subjective, several objective improvements did take place during the publication of their respective texts, as evidenced by the steady increase in readership numbers. Burlew and Hunt have developed their writing and art throughout the years, have won various awards for their webcomics during this time, and have achieved success to the point that they can consider their webcomic their main source of income. It is the similarities between these two webcomic cartoonists that the makes the differences in the interactions between them and their readers stand out, especially when it comes to their publication schedules.

Burlew began providing instalments of OOTS every Tuesday and Thursday. Like many webcomics, each instalment contained the equivalent of one comic book page worth of story and progressed the narrative forward while providing some humorous content. In webcomics, both the publication schedule of the instalments and the amount of narrative progression in each instalment impacts on the serial reading experience of the text. An example of this relationship in OOTS can be seen when Burlew planned for the titular group of protagonists to face off against a similar group of antagonists. Burlew intended to have six instalments of 'duel strips between the heroes and their evil counterparts' but decided to alter his usual publication schedule because updating only a twice a week:

would kill all the story momentum I had built... ... Rather than alter my plans, I merely accelerated the timetable and announced that for one week only... [OOTS $]$... would run every single day' (2005).

Here we see that the author perceived narrative pacing as surpassing the importance of the regular publication schedule. However, the 24 hour gap between each update meant that the enforced interruption was still present and helped to avoid the chance that an avid reader could miss an update during the event. Later on, the schedule would change to Monday, Wednesday and Friday updates and would continue this way for years. However, going through the forums one notices that the time of each individual publication would often be late into the evening of 
each day, sometimes past midnight of the scheduled date. With updates becoming less stable over time, Burlew announced that he would change the publication format to one where new instalments would be made available at random intervals and that small hiatuses would be made at the end of prevalent story arcs (2007). Reader reactions varied between anger and acceptance at this new updating schedule, but most realized the practical nature of adjusting their expectations for content per week. Burlew intended for instalments to still be made available three times a week. However, a new comic once a week was closer to the norm, with more instalments being a welcome surprise and less instalments becoming a source of worry for the readership.

In September 2012 a message from Burlew's wife appeared on the main page of his Giant in the Playground website, stating that Burlew had been in a car accident which had severely injured his dominant hand and that:

he won't be able to draw for at least six weeks (maybe longer, depending on how quickly the nerves in his thumb heal). And he didn't want to keep you guys in the dark for all that time. (2012a)

Burlew's decision to inform the readership of the bad news shows an authorial performance of keeping the readers in the loop. While he rarely talks about his personal life, Burlew makes an exception when it comes to things that actively affect the development of OOTS. Readers reacted with obvious concern and well wishes for the author but it did mean that the work was on standby for an indeterminate amount of time and fans worried if the webcomic would come back at all. Burlew provided a new instalment almost three months later, and the narrative content directly addressed the narrative pause by having one of the characters in the comic address the audience, saying:

Whoa, whoa, WHOAH! Guys! It's been like three months since the comic updated! You can't dive right into the tactical stuff like that! We need to remind everyone of what's been going on lately. We need a RECAP COMIC! (2012b).

The fourth wall breaking instalment summed up the current story arc and even poked fun at Burlew's injury as the publication schedule slowly returned to normal levels. Following the hiatus there was one other related period when the instalment rate of OOTS changed for reasons other than narrative priority. This change was due to a promise made by Burlew during a very successful Kickstarter campaign to help reprint the previous print compilations of OOTS instalments (2012c). Burlew had promised the readers upon reaching the one million dollar milestone that:

At some point this year, I'll give you all another week of seven OOTS strips in seven days (give or take another screw-up in the middle). I won't announce it until the first strip runs, but it will be sometime in 2012. What's more, I will add another day onto that run for every $\$ 100 \mathrm{k}$ we raise over a million (so we're almost at 8 comics right now) (2012d).

Two months after the return to updating post thumb injury, he informed his readers via another blog post: 
You've almost certainly noticed that I've been posting new comics every day, and some people have asked me if this is intended to fulfil my Kickstarter promise of nine comics in a row at some point. And the answer is: Maybe. I haven't actually finished all nine comics yet, and its possible my thumb might tell me, [No way, buddy,] before I do. If that happens, then this is just a nice little bonus run of comics for you, and the real nine-in-arow will happen some other time this year (2013). ${ }^{2}$

The rush of updates was done as a reward to the readers for their help in funding Burlew's reprint project and for their additional patience during the unexpected hiatus due to his injury. While the nine instalments depicted a very dramatic battle scene, such moments in the narrative had been done before and afterward at regular and irregular publication intervals, so the speedy nature of updating may have added an additional layer to the serial reading experience.

What makes the author-text-reader relationship so interesting in the case of OOTS is the fact that it is based on a world with clearly defined rules, thanks to its $D \& D$ setting. In a work of fantasy, an object like a magical potion that lets a person temporarily fly can be rare or almost nonexistent but in the context of a world dictated by the laws of gaming, a "potion of fly" costs 750 gold pieces and is quite common. Burlew directly acknowledges that such knowledge can tarnish the serial reading experience in a section of the OOTS FAQ page:

Q: In Strip \#X, why didn't character Y take action Z? If they had done so, they could have avoided a whole lot of trouble. A: You just answered your own question. The strip is ABOUT the trouble these characters get in; if a tactic would result in an effortless solution to their latest problem, there would be little point in showing it, see? The characters are woefully inefficient as a result, and often take actions that are rarely seen in a real D\&D game, like running away from moderate danger or 'forgetting' major abilities for the sake of a joke. But their foibles are what fuel the humor (2005).

The suspension of disbelief for the intended reader requires that they disregard knowledge of the rules of $D \& D$ and the tropes of adventuring in order to better enjoy the story. Still, the readership will come together to determine what level the characters are, flesh out possible statistics, and figure out what one character can do or not do in respects to their class and inventory. The wait for the next instalment leaves room for discussions not just on the direction of the narrative but also on the specificities of the characters. Burlew is aware of such speculations, and as a gamer himself, one particular authorial performance that comes with such a comic is to make sure that the narrative's continuity still fits within the framework and ruleset of this type of fantasy text. Thus, the genre as much as the medium of publication gives a defined shape to the story, while the readers constantly try to figure out where the specific borders lay.

Tarol Hunt faced similar struggles when determining a proper publication schedule for Goblins. He went through a few years of determining when updates should be made, culminating in an unconventional publication schedule. The original format that ran for years at a rate of twice a week (Tuesdays and Fridays) was too much of a struggle for him to keep up with, as evidenced

\footnotetext{
${ }^{2}$ Burlew's injury severely slowed down the rate of updates even after hiatus. Hence, his Kickstarter reward that was scheduled to happen at some moment in 2012 was delayed until 2013.
} 
by many late postings and missed updates alongside Twitter and blog post apologies. Hunt considered changing to once a week updates but feared that this would slow the pacing of his narrative too much. With this in mind, in late 2013 he decided to forego a specific day of the week and instead provide an update once every five days (Hunt 2013a). This was accompanied by the addition of a countdown clock to the website, so that readers would know almost to the minute when the next instalment would be available. Shortly after the change to the format, Hunt used the webcomic's blog feature to report that:

this five day schedule seems to be working out well. Y'see, the problem with twice a week, was that I couldn't keep up with that schedule and my updates were always late (as you know). The problem with once a week, is that it just feels too slow for the story. Five days seems to be the current sweet spot (2013b).

Readers enjoyed more consistency and Hunt had more time to invest in narrative production. This new and somewhat unconventional publication schedule only had a few delays or missed updates after its onset, which considering the previous format was quite an improvement. Until suddenly everything stopped.

For all the openness that Hunt exhibits on social media, there are still moments when information is not made available purposefully. One such event occurred after the publication of an instalment on February 12th, 2014. Hunt typically tweets as part of the authorial performances to keep his readers informed, especially in the time frame before and after he publishes a new instalment. The tweets following the February $12^{\text {th }}$ instalment were on par with Hunt's usual writing style:

I really don't like to brag about my own work or swear. Knowing this, you can understand the gravity of my next tweet. (2014a)

The next three pages of Goblins will blow your fucking minds. (2014b)

After a few more tweets about his everyday life, his authorial voice went silent for an extended period of time. The update clock was left blank and readers were left wondering what had happened. Hunt had shared many details about his life up to this point so the general consensus was that it had to be an extreme circumstance to keep him from his work and his fans. His wife, Danielle Stephens, who also helps with many of the logistics for Goblins' production had also stopped posting things in her respective avenues of social media. On February 26th, the following message was placed under the main website's blog posts: 'Very soon there will be a blog post from Tarol Hunt (Thunt), explaining what's happened and what's going on with the Goblins updates. This is not that blog. -Danielle' (2014c). Shortly thereafter, the countdown timer had a message indicating that updates were on hold for now. The message was later changed to say: 'Thunt is recuperating from a medical issue. Goblins will be returning to regular updates ASAP. We will keep you updated! Thank you for your patience! -Dukey' (2014d). The updated version came once speculation from the fans took hold of the forums about what the author's situation might be. 
On March 22nd, over a full month after the last instalment, Hunt posted on Twitter and provided some details as to what had happened. The abbreviated version of the situation was that Hunt suffered a nervous breakdown which left him emotionally distraught and unable to work on Goblins. While this explanation sufficed most of the fans' curiosity, Hunt insisted on publishing the full version of what had happened as he tweeted that, 'The blog will be posted purely because you [the readers] deserve to know why I just walked away from my responsibilities without a word for 5 weeks' (2014e). This tweet encompasses the dynamics of author-reader relationship within serialization. From the author's perspective, we can see that there is a sense of duty to continue to serialize over time and to keep the readership informed of the process. Hunt's choice to say that 'you deserve to know why' is not done as part of a contractual obligation but rather because he believes that the fans who have stuck with him through all other aspects of his authorial work and personal life should be informed. Hunt tweeted a few days later directly responding to the support that the readership had given him through a series of tweets quoted below.

I know "friends" isn't the most realistic word to describe most of you, since honestly, I don't know many or your faces or names (2014f).

But "fans" is such a crap term too. You helped my with the down payment to buy my house. You helped me become a better artist/writer... (2014g)

... and now you've played no small part in helping me through... whatever you call this. You've literally saved my mind, if not my life (2014h).

The author's lack of a clear identifying term for his readership indicates that there is more to the audience of the work than just passive receptors of communication through literature. There is support at the financial level (helping to buy a house) alongside the emotional aspect which in Hunt's case helped him overcome the most gruelling challenge of his life as an author and as a person. On May 8th, the long awaited blog post titled 'I Quit' was finally published on the Goblins website (2014i). The incredibly long and detailed explanation provided many details as to how for the better part of two months, Hunt's emotional demons were too much. He detailed how his sense of guilt over not being able to achieve deadlines for new instalments as well as other authorial performances had gotten to the point where he had isolated himself from his readership and his life. The struggles (which he personifies in the blog post as 'Guilt Vader') engulfed Hunt in paralyzing worry where no work could be done on the webcomic and his interpersonal relationships became in peril.

In the end, his wife Danielle helped him get out of his shell of misery and back to drawing and writing. She has worked on Goblins in various roles since its onset but perhaps her most important role is supporting her partner. If authorship in serial fiction depends on the maintenance of the means of narrative production, then authorial performances extend beyond the author to those around him/her and even to the readership. In the case of Tarol Hunt and Danielle, we see a clear support system in place that is key for keeping the story (and life itself) from stopping. However, it is not just the two of them that keep Goblins going as the readership also undertakes similar authorial performances to financially and emotionally support the work 
as it is serialised. Hunt explains that his mental breakdown and recovery led to a change in how he perceived the relationship with his readers.

From the very beginning, I've treated my readers as my bosses. After all, that's where my income originates from, right? And when I'm late, it's you the readers who are tapping your watches disapprovingly. And in a way, you could fire me simply by not reading my comic anymore. The relationship fits! And for years, it's felt as though I'd be disrespecting my readers if I were to treat the relationship any other way. But there's been a problem with this dynamic... But while this can work in a lot of business situations, it's downright destructive in the reader/webcomic author relationship. I mean... let's be honest, the internet is not an air-tight bastion of complete, unwavering good advice. There are some bad ideas floating around out there. (2014i)

Hunt went on to say that he considered reader feedback as if it were coming from one of many superiors. He had reversed the long established concept that the author was above the reader and had given them all the power in this relationship. Hunt believed he was subservient to the reader and to a point he felt bullied and even enslaved to them. His declaration of "quitting" was not about ceasing to be an author but rather of changing the dynamic he had developed and fostered. 'I mean that I no longer work for any of you. I'll no longer create Goblins with a fear of failure looming over me.' (2014i) While the financial and emotional dimensions of webcomic authorship are still in play, Hunt stated that he will continue his narrative for his readers but that he will no longer treat them as his bosses.

I'm still creating Goblins and I'm still fully respecting those that deserve my respect. I'm still listening to advice and criticism and I'm still as interactive with my readers as I can be. The only difference is that I no longer consider any of you to be my boss and as a result, I now have a right to place my own opinions about myself and my work, above yours (2014i).

By shifting the power dynamics of the author-reader relationship, Hunt established that his work would not be put out for the sake of success but rather because he wanted to continue telling his story and hoped that the readers would still be there for him. The publication schedule continued to be erratic (and as of the time of this writing, still is) and he knows that this may cause some to cease the serial reading experience of Goblins. He stated, 'I completely understand and I'll respect your decision to walk away. I won't respect your angry emails, because I don't work for you anymore. I quit' (2014i).

The next instalment of Goblins was published on September $17^{\text {th }}$, a full seven months after the last update. In that extended, enforced interruption, the narrative of Goblins completely stopped but the tasks of readers to periodically visit the site did not. They no longer came to see if the heroes would survive the deadly encounter but rather to see if there was any word from the author. The mystery eventually led to answers but visiting the website for a time stopped being about the work and instead became about Hunt's real life story. This example perfectly illustrates the author-reader dynamic in contemporary serial fiction. Within serialisation, the continuation of the text occurs parallel to the author's biography, which is updated through social media and blog posts within the same comic. The act of reading then is not limited to the narrative 
surrounding the characters but rather extends to the temporal present of the author. Thus, readers interact with the primary and ancillary texts directly with the author in addition to their own communication as a community through the website's forums. The text now encompasses all of these digital documents. While all parts are not necessarily integral to understanding the overarching story, it does provide additional context and insight into the narrative production of the webcomic in almost real time, should the author wish to divulge said information.

While much of this argument revolves around the practice of waiting for the next piece of serial fiction to become available via publication, there is one more element that should be discussed on the other side of the digital coin of serialised storytelling. As instalments are developed and even after the narrative is officially completed, readers still have access to the archives which contain all the parts of the story so far. In digital storytelling and especially in comics, the archive is maintained as part of the document of the website. The task of compiling all previous instalments is an authorial performance, which runs contrary to the previous practice in print of the reader being responsible for this task. If serialisation is about the present text waiting for future additions, one must also recognize the importance of past instalments being readily available at any moment. The temporal and spatial pause of serialisation is skipped as the wait for more content is just a click away. Readers who are not up to date with the serial experience now have the ability to catch up if they have enough time on their hands. Those who decide to read a vast amount of instalments over a short period of time are said to take part of what the $T V$ Tropes wiki calls an 'archive binge', much in the same way that one can see multiple episodes of a show in one sitting through an archive such as a DVD or instant streaming service.

The advantage to this form of reading is that patience is not a factor in gaining access to the most recent instalment. However, I argue that the lack of an enforced interruption takes away from the intended reading and factors out the communal aspects of the serial reading experience. In my research, I have found that there is a communal element when it comes to reading serialized works and that the pause between instalments leads not only to reflection but also to discussion with other readers about what has happened and will happen next. These interactions are a part of the history of serial fiction dating back to the works of Charles Dickens. As readers come together, emotional connections are built and public opinion is established to the point that the text can be altered before its official publication. In the case of Dickens:

Bulwer Lytton protested against the original conclusion to Great Expectations as too downbeat, leading Dickens to substitute one in which the eventual reunion of Pip with Estella is, at the very least, a possibility (Flint 2001, 25).

Nowadays these conversations can also include the author's voice, thanks to forums and social media. Just because there is a temporal pause in the story does not mean that the readers' engagement with it stops as well. By removing the interruption, there is no longer time for conversation and thus reading becomes a solitary endeavour. Without these breaks, the pause for dramatic effect between instalments is lost and the need to find out what happens next supersedes the desire to comprehend what just happened. Thus, the serial reading experience of a text is a fairly unique experience that cannot be replicated outside of initial publication. However, the digital documents on which these webcomics are published trace the dynamics of the author-reader relationship. Engaging with a serialized text requires accessibility, not only to 
previous instalments but to future ones as well, even if the original spatial and temporal intermissions are no longer part of the reading experience. If as the old saying goes, absence makes the heart grow fonder, then it is the act of waiting for additional content that allows for a greater emotional investment in the narrative and for a larger discussion in the reading community to take place.

\section{References}

Balder, R. (2009) 'Re: Quick Question', [e-mail].

Balder, R. (2006) Erfworld, [online]. Available at http://www.erfworld.com/erf_stream/view. Accessed 7 April 2015.

Bryant, J. (2002) The Fluid Text: A Theory of Revision and Editing for Book and Screen, Ann Arbor: University of Michigan Press.

Burlew, R. (2003) The Order of the Stick, [online]. Available at http://www.giantitp.com/comics/oots0001.html. Accessed 16 November 2014.

Burlew, R. (2005) 'Giant in the Playground FAQ Page', [online]. Available at http://www.giantitp.com/FAQ.html. Accessed 4 March 2015.

Burlew, R. (2005) The Order of the Stick: Dungeon Crawlin' Fools, Philadelphia: Giant in the Playground.

Burlew, R. (2005) 'Re: Order of the Stick: November II', [online]. Available at http://www.giantitp.com/forums/showthread.php?6495-Order-of-the-Stick-NovemberII/page17\&p=291639\#post291639. Accessed 16 November 2014.

Burlew, R. (2007) 'Three-a-week (on average)', [online]. Available at http://web.archive.org/web/20071130043354/http://www.giantitp.com/index.html\#RD4e Kf1OFBCveGJ2pdt. Accessed 7 April 2015.

Burlew, R. (2012a) 'Important Announcement; Please Read', [online]. Available at http://www.giantitp.com/index.html. Accessed 4 March 2015.

Burlew, R. (2012b) '\#864 Bet It would Get Funded on Kickstarter', [online]. Available at http://www.giantitp.com/comics/oots0864.html. Accessed 16 November 2014.

Burlew, R. (2012c) 'Order of the Stick Reprint Drive', [online]. Available at https://www.kickstarter.com/projects/599092525/the-order-of-the-stick-reprintdrive/description. Accessed 7 April 2015.

Burlew, R. (2012d) 'Update \#26: Eye of the Pig, Baby. Eye of the Pig', [online]. Available at https://www.kickstarter.com/projects/599092525/the-order-of-the-stick-reprintdrive/posts/177799. Accessed 7 April 2015.

Burlew, R. (2013) 'Update on Thumb', [online]. Available at http://www.giantitp.com/index.html. Accessed 4 March 2015.

Burns-White, E. (2004) 'FAQ: Lexicon', [online]. Available at http://www.websnark.com/archives/2004/09/faq_lexicon.html. Accessed 16 November 2014.

Campbell, T. (2006) A History of Webcomics v1.0, San Antonio: Antarctic Press.

Flint, K. (2001) 'The Victorian Novel and its Readers', in D. David (ed.), The Cambridge Companion to The Victorian Novel, Cambridge: Cambridge University Press. pp. 17-36 
Guigar, B. (2009) '... But What About Long-Form Comics?', [online]. Available at http://webcomics.com/site-news/but-what-about-long-form-comics/. Accessed 4 March 2015.

Guigar, B. Kellett, D. Kurtz, S. and Straub, K. (2008) How to Make Webcomics, Berkeley: Image Comics.

Hughes, L. and Lund, M. (1991) The Victorian Serial: Victorian Literature and Culture Series 8, Charlottesville: University Press of Virginia.

Hunt, T. (2005) Goblins: Life through Their Eyes, [online]. Available at http://www.goblinscomic.org/. Accessed 16 November 2014.

Hunt, T. (2009) 'The Introduction to Goblins', [online]. Available at http://www.goblinscomic.org/06252005/. Accessed 16 November 2014.

Hunt, T. (2013a) 'Big Changes for Goblins', [online]. Available at http://www.goblinscomic.org/big-changes-for-goblins/. Accessed 7 April 2015.

Hunt, T. (2013b) 'Countdown Clocks and Dragon Slaying', [online]. Available at http://www.goblinscomic.org/countdown-clocks-and-dragon-slaying/. Accessed 7 April 2015.

Hunt, T. (2014a) 'I really don't like to brag about my own work or swear. Knowing this, you can understand the gravity of my next tweet.', [Twitter]. 15 February 2014. Available at https://twitter.com/Thunt_Goblins/status/434832219408830464.

Accessed 7 April 2015.

Hunt, T. (2014b) 'The next three pages of Goblins will blow your fucking minds.', [Twitter]. 15 February 2014. Available at https://twitter.com/Thunt_Goblins/status/434832567980658690. Accessed 7 April 2015.

Hunt, T. (2014c) 'This Is Not The Blog', [online]. Available at http://www.goblinscomic.org/this-is-not-the-blog/. Accessed 7 April 2015.

Hunt, T. (2014d) 'Countdown Clock Special Message', [online]. Available at http://web.archive.org/web/20140625101346/http://www.goblinscomic.org/. Accessed 7 April 2015.

Hunt, T. (2014e) 'The blog will be posted purely because you deserve to know why I just walked away from my responsibilities without a word for 5 weeks.', [Twitter]. 23 March 2014. Available at https://twitter.com/Thunt_Goblins/status/447585952454569984. Accessed 7 April 2015.

Hunt, T. (2014f) 'I know "friends" isn't the most realistic word to describe most of you, since honestly, I don't know many or your faces or names.', [Twitter]. 29 March 2014. Available at https://twitter.com/Thunt_Goblins/status/449839549628166145. Accessed 7 April 2015.

Hunt, T. (2014g) 'But "fans" is such a crap term too. You helped my with the down payment to buy my house. You helped me become a better artist/writer...', [Twitter]. 29 March 2014. Available at https://twitter.com/Thunt_Goblins/status/449840010888364032. Accessed 7 April 2015.

Hunt, T. (2014h) '...and now you've played no small part in helping me through... whatever you call this. You've literally saved my mind, if not my life.', [Twitter]. 29 March 2014. Available at https://twitter.com/Thunt_Goblins/status/449841741680476160. Accessed 7 April 2015.

Hunt, T. (2014i) 'I Quit', [online]. Available at http://www.goblinscomic.org/i-quit/. Accessed 16 November 2014. 
Internet Archive (1996) 'Wayback Machine', [online]. Available at http://archive.org/web/ Accessed April 7, 2015.

Morrison, G. and Kubert A. (2006) 'Batman and Son Part 1: Building a Better Batmobile', Batman \#655. New York: DC Comics.

Morrison, G. and Garbett, L. (2008) 'Last Rites: What the Butler Saw', Batman \#683. New York: DC Comics.

Shillingsburg, P. (1997) Resisting Texts: Authority and Submission, Ann Arbor: University of Michigan Press.

Tanselle, G. (1992) A Rationale of Textual Criticism, Philadelphia: University of Pennsylvania Press.

TV Tropes (2015) 'Archive Binge', [online]. Available at http://tvtropes.org/pmwiki/pmwiki.php/Main/ArchiveBinge. Accessed 7 April 2015.

Tweet, J. Cook, M. and Williams, S. (2003) Dungeons \& Dragons Player's Handbook: Core Rulebook 1, v. 3.5, Renton: Wizards of the Coast.

Gabriel Romaguera is a PhD Candidate in English from the University of Rhode Island. He has a BA and an MA in English from the University of Puerto Rico at his hometown of Mayaguez. He studies serialization across different times and media. Gabriel hopes to become a professor and help others understand the power of storytelling found in literature and popular culture. He is the founder of the International Council for Webcomic Analysis in Academia (ICWAA), where he helps scholars that study this medium come together and share ideas.

Email: gromaguera@gmail.com 